\title{
Naturally-occurring, osmo-remedial variants of Escherichia coli
}

\author{
C. M. KUNIN, H. H. TONG and W. E. MAHER
}

Department of Internal Medicine, The Ohio State University, Columbus, Ohio 43210, USA

\begin{abstract}
Summary. Two clones of Escherichia coli $\mathrm{O} 27: \mathrm{K} 1: \mathrm{H} 31$ and $\mathrm{O} 2: \mathrm{H} 7$, isolated from patients with urinary tract infection or bacteraemia, failed to grow in a synthetic minimal medium (MM) of low osmolality. They were considered to be osmo-remedial because they grew well when sufficient amounts of $\mathrm{NaCl}$, mannitol or sucrose were added to raise the osmolality of the medium to $>300 \mathrm{mOsm} / \mathrm{kg}$. The defect could also be corrected by nicotinamide or its precursors quinolinic and aspartic acids. Each clone had a unique DNA restriction enzyme profile, fimbriae and antibiotic susceptibility patterns. The osmo-remedial variants were unstable and underwent phenotypic modulation to form mixtures with osmo-tolerant forms when grown in MM. They tended to form satellites of small colonies around large colonies of osmo-tolerant cells on MM agar plates. The penicillin method of Davis was used to separate the two forms. Nicotinamide induced the expression of $o m p F$ when the osmo-remedial strains were grown under conditions of low osmolality. It is possible that the variants are defective in the synthesis of membrane-derived oligosaccharides or outer-membrane proteins, but this has yet to be determined.
\end{abstract}

\section{Introduction}

Most strains of Escherichia coli can grow in synthetic minimal media containing salts, trace metals and a simple source of carbon and nitrogen such as glucose and ammonium. They can tolerate changes in osmolality of the medium in the range $150-1200 \mathrm{mOsm} / \mathrm{kg}$. ${ }^{1}$ Naturally-occurring auxotrophic variants have been isolated from the faeces of healthy individuals and from patients with urinary tract infections (UTI), bacteraemia and meningitis. The most common nutritional requirement is for nicotinamide ${ }^{2-4}$ but some strains require cysteine, thiamine, thymidine, glutamine or various amino acids. ${ }^{5.6}$

During the course of a study of the salt tolerance of clinical isolates of E. coli, we encountered several strains of two serotypes, $\mathrm{O} 27: \mathrm{K} 1: \mathrm{H} 31$ and $\mathrm{O} 2: \mathrm{H} 7$, which failed to grow in minimal medium of low osmolality. They were regarded as osmo-remedial because they grew well when sufficient $\mathrm{NaCl}$, mannitol, or sucrose was added to raise the osmolality of the medium to $>300 \mathrm{mOsm} / \mathrm{kg}$. The defect could also be corrected by the addition of small amounts of nicotinamide. The strains were found to consist of mixtures of osmo-remedial and osmo-tolerant variants. This suggested that they might be undergoing phenotypic modulation.

We describe the isolation and characterisation of these strains. A variation of the penicillin method, designed to isolate auxotrophic mutants of $E . c$ oli, ${ }^{7}$ enabled us to isolate the osmo-remedial variants, to study their osmotic and nutritional requirements and to characterise their outer-membrane proteins (OMPs).

\section{Materials and methods}

\section{Bacterial strains}

Clinical isolates of E. coli were obtained from 100 patients with bacteraemia, 101 young women with UTI, 100 rectal swabs from healthy individuals and 15 vaginal swabs from postmenopausal women. E. coli K 10 was provided by Dr L. Tombras Smith of the University of California, Davis. ${ }^{8}$ E. coli ATCC 25922 was obtained from the American Type Culture Collection. Stock cultures, from a single colony of each isolate, were grown in Schaedler's Broth (Difco) containing glycerin $15 \%$ and stored at $-40^{\circ} \mathrm{C}$.

\section{Media and chemicals}

Minimal medium (MM) ${ }^{9}$ was composed of $(/ \mathrm{L})$ glucose $2 \mathrm{~g}$, dipotassium phosphate $10.5 \mathrm{~g}$, monopotassium phosphate $4.5 \mathrm{~g}$, sodium citrate $0.5 \mathrm{~g}$, magnesium sulphate $0.264 \mathrm{~g}$ and ammonium sulphate $1 \mathrm{~g}$. The $\mathrm{pH}$ was adjusted to $7 \cdot 2$ before use. The osmolality was $231 \mathrm{mOsm} / \mathrm{kg}$ as determined by freezing point depression. Solid MM (SMM) was prepared by the 
addition of Bacto-Agar (Difco) $2 \%$. The batch of agar contained $0.34 \mathrm{~mm} \mathrm{NaCl} / \mathrm{g}$, as determined at the Clinical Laboratories of the Ohio State University Hospital. In some experiments, the medium was supplemented with nicotinamide, nicotinic acid, quinolinic acid, aspartic acid, oxalacetic acid, glycine betaine, choline, thiamine, MEM non-essential and MEM essential amino acid mixtures, or ampicillin (Sigma). Other media or reagents included Trypticase Soy Broth (TSB, osmolality $301 \mathrm{mOsm} / \mathrm{kg}$ ), Trypticase Soy Agar (TSA) (BBL Laboratories, Cockeysville, MD, USA), Mueller-Hinton Broth and penicillinase ( $\beta$-lactamase) (Difco).

\section{Growth conditions}

A single colony from MacConkey agar was subcultured in $\mathrm{MM}$ and incubated overnight at $37^{\circ} \mathrm{C}$. A 1 in 200 dilution of a $0.5 \mathrm{McF}$ arland standard (final concentration $c .5 \times 10^{5} \mathrm{cfu} / \mathrm{ml}$ ) was added to tubes containing $\mathrm{MM}$ alone or with graded concentrations of $\mathrm{NaCl}(0 \cdot 1-1 \mathrm{M}$ in $0.1 \mathrm{M}$ steps). Growth was assessed visually at $24 \mathrm{~h}$ and by optical density at $48 \mathrm{~h}$ with a Milton Roy spectrophotometer (Spectronic 601, Rochester, NY, USA) set at $600 \mathrm{~nm}$. The end-point for salt tolerance was the maximum concentration of $\mathrm{NaCl}$ at which turbidity was $\geqslant 50 \%$ (absorbance of $c$. 0.5 ) when compared with tubes in which there was full growth. In each experiment, $E$. coli strains $\mathrm{K} 10$ and ATCC 25922 were included as controls.

\section{Serological typing and identification of $P$ fimbriae}

Strains were characterised by Dr C. Krishnan (Ontario, Canada Ministry of Health Laboratories) by O, $\mathrm{Kl}$ and $\mathrm{H}$ antigen and haemolysin production. $\mathrm{P}$ fimbriae were identified with latex particles to which $\alpha$-D-Gal(-1-4)- $\beta \mathrm{D}$-Gal-disaccharide was covalently bonded (PF Test, Orion Diagnostica, Espoo, Finland).

\section{Antimicrobial drug susceptibility}

The tests were performed in standardised microwell dilution plates prepared by the Clinical Microbiology Laboratory of the Ohio State University.

\section{Isolation of osmo-remedial E. coli with ampicillin and penicillinase}

A modification of the penicillin method described by Davis $^{7}$ was used to isolate the osmo-remedial strains. A 0.001-ml loopful of a single colony was picked from a TSA plate and incubated in TSB overnight at $37^{\circ} \mathrm{C}$. The culture was centrifuged for $15 \mathrm{~min}$ at $5000 \mathrm{~g}$ and the pellet was washed three times with $10 \mathrm{ml}$ of MM. The cells were adjusted to a 0.5 McFarland unit and then diluted $1 \times 10^{4}$ in $\mathrm{MM}$ containing ampicillin $100 \mathrm{mg} / \mathrm{L}$. After incubation for $24 \mathrm{~h}$ at $37^{\circ} \mathrm{C}, 1000$ units of penicillinase were added and the mixture was incubated for $4 \mathrm{~h}$ at $30^{\circ} \mathrm{C}$. The treated cells $(0 \cdot 1 \mathrm{ml})$ were added to tubes containing $0.9 \mathrm{ml}$ of $\mathrm{MM}$ alone or $\mathrm{MM}$ with added $\mathrm{NaCl}, \mathrm{KCl}$, sucrose; mannitol, nicotinamide or other compounds. The tubes were incubated at $37^{\circ} \mathrm{C}$ and observed for turbidity daily for 5 days. Quantitative cultures were performed on TSA, just before addition of the ampicillin, $24 \mathrm{~h}$ later and $24 \mathrm{~h}$ after the penicillinase had been added.

\section{Preparation of cell extracts for outer-membrane proteins (OMPs)}

OMPs were prepared by differential centrifugation of crude sonicates obtained from overnight cultures grown in various media and purified by treatment with sodium- $\mathrm{N}$-lauryl sarcosinate. ${ }^{10}$ They were resolved by vertical slab gel electrophoresis and stained with Coomassie Brilliant Blue.

\section{DNA analysis}

Bacterial chromosomal DNA was isolated according to the method of Van Ketel et al. ${ }^{11}$ Briefly, bacteria were grown in TSB at $37^{\circ} \mathrm{C}$ in shaker flasks. Centrifuged pellets were washed in $10 \mathrm{~mm}$ Tris- $\mathrm{HCl}-10 \mathrm{~mm}$ disodium EDTA, pH 8.5, and treated with lysozyme $1 \mathrm{mg} / \mathrm{ml}$ and sodium dodecyl sulphate (Sigma) $1 \%$. RNAase A $200 \mu \mathrm{g} / \mathrm{ml}$ (Sigma) was added ${ }^{12}$ and the solution was incubated overnight at $50^{\circ} \mathrm{C}$ with proteinase K (Sigma) $100 \mathrm{mg} / \mathrm{L}$. After treatment with $1 \mathrm{M}$ sodium perchlorate, the DNA was extracted with phenol-chloroform-isoamyl alcohol and precipitated with ethanol $95 \%$. The DNA was digested with EcoRI (Gibco BRL, Gaithersburg, MD). Restriction enzyme digests were electrophoresed in agarose $0.3-0.5 \%$ in a Tris-acetate-EDTA buffer system ${ }^{13}$ with high-mol. wt DNA markers (Gibco BRL). Gels were stained in ethidium bromide $0.5 \mathrm{mg} / \mathrm{L}$, destained in distilled $\mathrm{H}_{2} \mathrm{O}$ and photographed under UV illumination.

\section{Results}

\section{Isolation of osmo-remedial strains of E. coli}

The clinical isolates of E. coli were screened for ability to grow in MM $(231 \mathrm{mOsm} / \mathrm{kg})$ alone, or in the presence of serial $0.1 \mathrm{M}$ increments of $\mathrm{NaCl}$. Five strains of E. coli $\mathrm{O} 27: \mathrm{K} 1: \mathrm{H} 31$ and one strain of $\mathrm{O}$ ?: $\mathrm{H} 31$ failed to grow in MM by $48 \mathrm{~h}$. Five of the six strains were isolated from patients with UTI and one was from a patient with bacteraemia. All the strains were relatively salt-tolerant (growing in $0.5-0.6 \mathrm{M}$ $\mathrm{NaCl}$ ), non-haemolytic and lacked $\mathrm{P}$ fimbriae. All but one strain were susceptible to representative $\beta$-lactam and aminoglycoside antibiotics and to co-trimoxazole. One strain was resistant to cephalothin. All of the strains were resistant to erythromycin $>4 \mathrm{mg} / \mathrm{L}$ and vancomycin $>16 \mathrm{mg} / \mathrm{L}$.

Six strains of E. coli $\mathrm{O} 2: \mathrm{H} 7$ were osmo-remedial, failing to grow in $\mathrm{MM}$ without addition of $\mathrm{NaCl}$. Two 


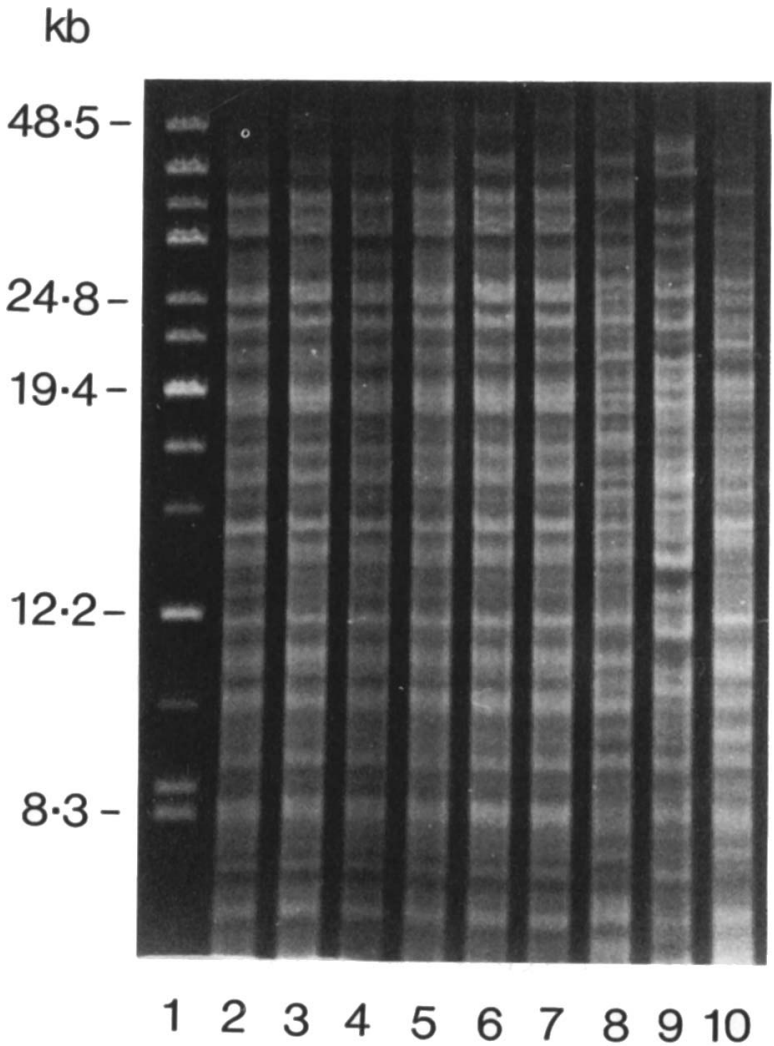

Fig. 1. Restriction fragment analysis (EcoRI digest). Lane 1, $\mathbf{M}_{\text {r }}$ markers; 2-7, different isolates of $E$. coli $\mathrm{O} 27: \mathrm{K} 1: \mathrm{H} 31 ; 8, E$. coli ATCC $25922 ; 9$, E. coli $\mathrm{K} 10 ; 10, E$. coli $\mathrm{O} 2: \mathrm{H} 7$.

of these strains had been isolated from urine, two from blood cultures, one from stool and one from a vaginal swab. All the strains were relatively salt-tolerant (growing in $0.5-0.7 \mathrm{M} \mathrm{NaCl}$ ), non-haemolytic and possessed $P$ fimbriae. They varied in their susceptibility to antibiotics. Most were susceptible to all the antibiotics tested but two strains were resistant to ampicillin-sulbactam and amoxycillin-clavulanate. All were resistant to erythromycin $>4 \mathrm{mg} / \mathrm{L}$ and vancomycin $>16 \mathrm{mg} / \mathrm{L}$.

\section{DNA chromosomal analysis of the osmo-remedial strains}

The restriction patterns obtained from $E$. coli O27:K1:H31 strains were similar to each other, but differed from those of $E$. coli ATCC 25922, K10 and $\mathrm{O} 2: \mathrm{H} 7$ (fig. 1). All strains of $E$. coli $\mathrm{O} 2: \mathrm{H} 7$ exhibited identical patterns.

\section{Growth requirements of the osmo-remedial strains of E. coli}

The strains were not killed when added to MM. They could be "rescued", and even after 3-5 days achieved full growth within $24 \mathrm{~h}$ after addition of any of several compounds, including various salts or sugars to an osmolality of $300 \mathrm{mOsm} / \mathrm{kg}$ and very low concentrations of nicotinamide, and some of its precursors (table I).
Initial attempts to isolate the osmo-remedial strains in pure culture

The osmo-remedial strains were, at times, found to grow in MM without added salt. This was noted even when single colonies were passed several times on SMM to avoid nutrient carry over. The effect appeared to be lost in some experiments or growth was delayed unless $\mathrm{NaCl}$ or nicotinamide was added. This was particularly common with several strains of $E$. coli $\mathrm{O} 2$ : $\mathrm{H} 7$.

More consistent results were obtained when a low inoculum of $c .1 \times 10^{4} \mathrm{cfu} / \mathrm{ml}$ was used. This led to the suspicion that each colony might be a mixture of osmo-remedial and osmo-tolerant cells. This notion was supported by experiments in which a single colony was picked from MacConkey agar, serially diluted and plated on SMM, or SMM with $\mathrm{NaCl} 0.2 \mathrm{M}$, or nicotinamide $0 \cdot 1 \mathrm{~mm}$. Uniform, large colonies were noted after incubation for $48 \mathrm{~h}$. In a representative experiment there were $1.4 \times 10^{4} \mathrm{cfu} / \mathrm{ml}$ on SMM, 3.5 $\times 10^{7} \mathrm{cfu}$ on $\mathrm{SMM}+\mathrm{NaCl}$ and $6.8 \times 10^{7} \mathrm{cfu}$ on the $\mathrm{SMM}+$ nicotinamide. Thus, there were about 1000 times more osmo-remedial than osmo-tolerant colonies in the culture. Subcultures of colonies taken from SMM grew in $\mathrm{MM}$ and $\mathrm{MM}+0.2 \mathrm{M} \mathrm{NaCl}$, whereas those taken from $\mathrm{SMM}+\mathrm{NaCl}$ grew only in $\mathrm{MM}+0.2 \mathrm{M} \mathrm{NaCl}$. It appeared as though osmoremedial strains had been isolated in $\mathrm{MM}+\mathrm{NaCl}$ and osmo-tolerant strains in plain MM. However, subcultures of the putative osmo-remedial isolates grew well when streaked on SMM and appeared to have reverted to osmotic tolerance.

Tiny colonies were observed to grow on SMM after about $72 \mathrm{~h}$. They were not found on SMM containing $\mathrm{NaCl}$ or nicotinamide. Six sets of the tiny colonies were cut from the agar and subcultured in $\mathrm{MM}$ or $\mathrm{MM}+\mathrm{NaCl}$. Three of the sets grew in $\mathrm{MM}+\mathrm{NaCl}$ only, whereas the other sets grew in $\mathrm{MM}$ or $\mathrm{MM}+$ $\mathrm{NaCl}$. This experiment was repeated several times with similar results. Thus, it was not possible consistently to separate the osmo-remedial from the osmo-tolerant forms by sequential subculture in $\mathrm{MM}+\mathrm{NaCl}$ and $\mathrm{SMM}+\mathrm{NaCl}$, by terminal dilution or by isolation of individual tiny colonies.

\section{Use of ampicillin with penicillinase rescue to isolate osmo-remedial E. coli}

This approach was based on the concept that the osmo-tolerant variants would grow in MM and be killed by ampicillin, whereas the osmo-remedial variants would not grow in $\mathrm{MM}$ and therefore not be killed. The osmo-remedial variants would then be rescued by addition of osmolytes or nicotinamide, once the ampicillin had been inactivated by penicillinase.

This method proved to be effective for the isolation of the osmo-remedial strains of $E$. coli. Two strains of E. coli $\mathrm{O} 27: \mathrm{K} 1: \mathrm{H} 31$, six strains of $\mathrm{O} 2: \mathrm{H} 7$ and the control strains of $E$. coli ATCC 25922 and K10 were 


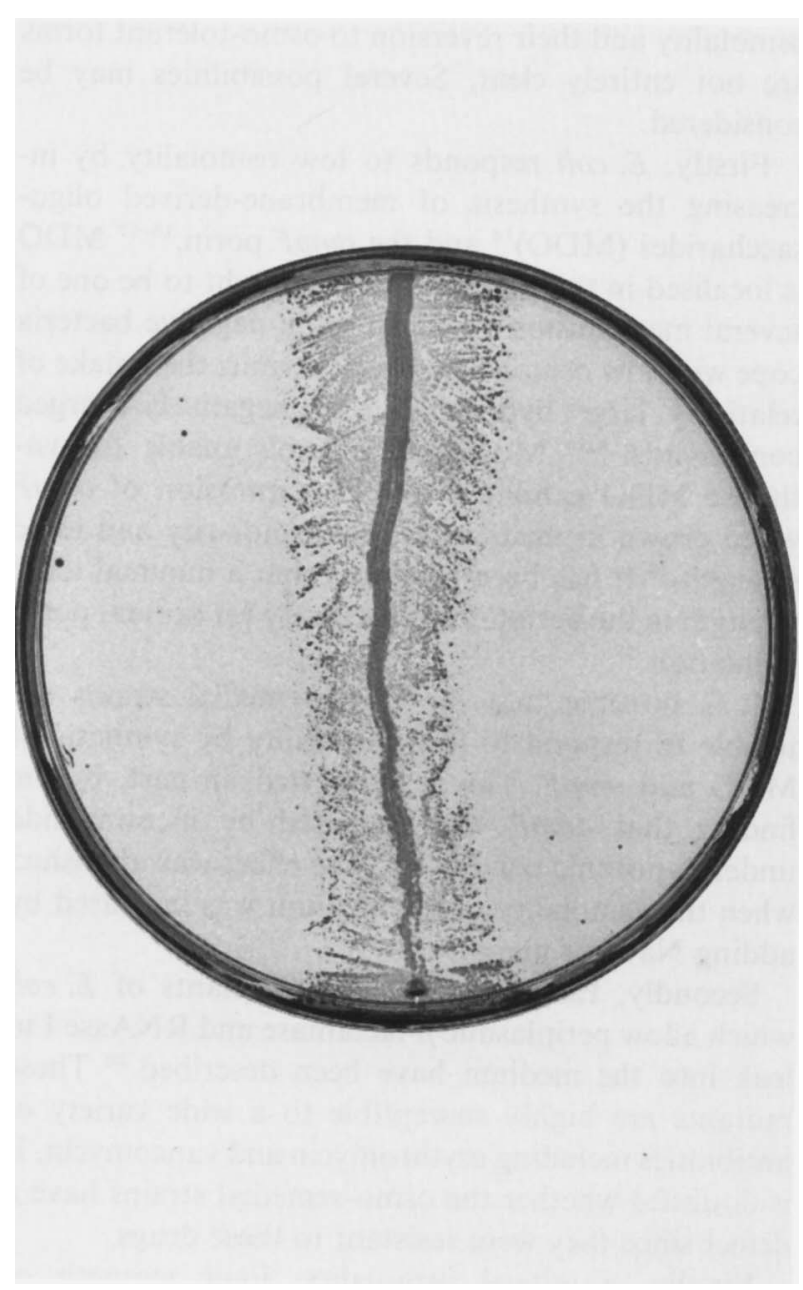

Fig. 2. Satellite phenomenon demonstrated on MMA. The surface of the plate was inoculated uniformly with an osmo-sensitive strain of $E$. coli $\mathrm{O} 27: \mathrm{K} 1: \mathrm{H} 31$ and then $E$. coli $\mathrm{K} 10$ was streaked across its diameter.

studied. Ampicillin $(100 \mathrm{mg} / \mathrm{L})$ reduced the inoculum of all strains in MM from $c .1 \times 10^{3} \mathrm{cfu}$ to $<1 \times 10^{1} \mathrm{cfu}$ within $24 \mathrm{~h}$. After addition of penicillinase, the control strains of $E$. coli ATCC 25922 and K10 became turbid
Table I. Compounds that supported growth in MM of osmoremedial strains of $E$. coli $\mathrm{O} 27: \mathrm{K} 1: 31$ and $\mathrm{O} 2: \mathrm{H} 7$

\begin{tabular}{lc}
\hline Compound* & $\begin{array}{c}\text { Minimal } \\
\text { concentration that } \\
\text { supported growth }\end{array}$ \\
\hline $\mathrm{NaCl}$ & $0.1 \mathrm{M}$ \\
$\mathrm{KCl}$ & $0.1 \mathrm{M}$ \\
Mannitol & $0.2 \mathrm{M}$ \\
Sucrose & $0.2 \mathrm{M}$ \\
Nicotinamide & $<0.1 \mathrm{mM}$ \\
Quinolinic acid & $1.0 \mathrm{~mm}$ \\
Aspartic acid & $0.1 \mathrm{~mm} \dagger$
\end{tabular}

* Glutamic acid, oxalacetic acid, glycine betaine, choline and thiamine were not active at $1 \mathrm{mM}$. A mixture of essential amino acids did not restore growth.

$\dagger$ Supported growth of E. coli $\mathrm{O} 2: \mathrm{H} 7$ only.

within $24-48 \mathrm{~h}$. Tubes containing the osmo-remedial strains in $\mathrm{MM}$ alone remained clear for $\geqslant 5$ days. Identical tubes which contained osmolytes, nicotinamide or its precursors became turbid within 1-2 days. The ampicillin-penicillinase method was less effective with larger inocula, smaller amounts of ampicillin $(20 \mathrm{mg} / \mathrm{L})$, or when the strains were grown in MM rather than TSB before addition of the ampicillin.

\section{Satellite phenomenon with osmo-remedial strains}

Despite the apparent success of the ampicillinpenicillinase method for the isolation of osmo-remedial variants, reversion to osmo-tolerance still occurred. This was observed when subcultures from $\mathrm{MM}$ containing $\mathrm{NaCl}$, mannitol or nicotinamide were plated on SMM. A mixture of large and tiny colonies was observed on SMM even at a dilution of $1 \times 10^{-7}$. The tiny colonies tended to grow as satellites around large colonies.

To examine this phenomenon further, the surface of SMM was uniformly inoculated with E. coli $\mathrm{O} 27: \mathrm{K} 1: \mathrm{H} 31$ that had been exposed to ampicillin and

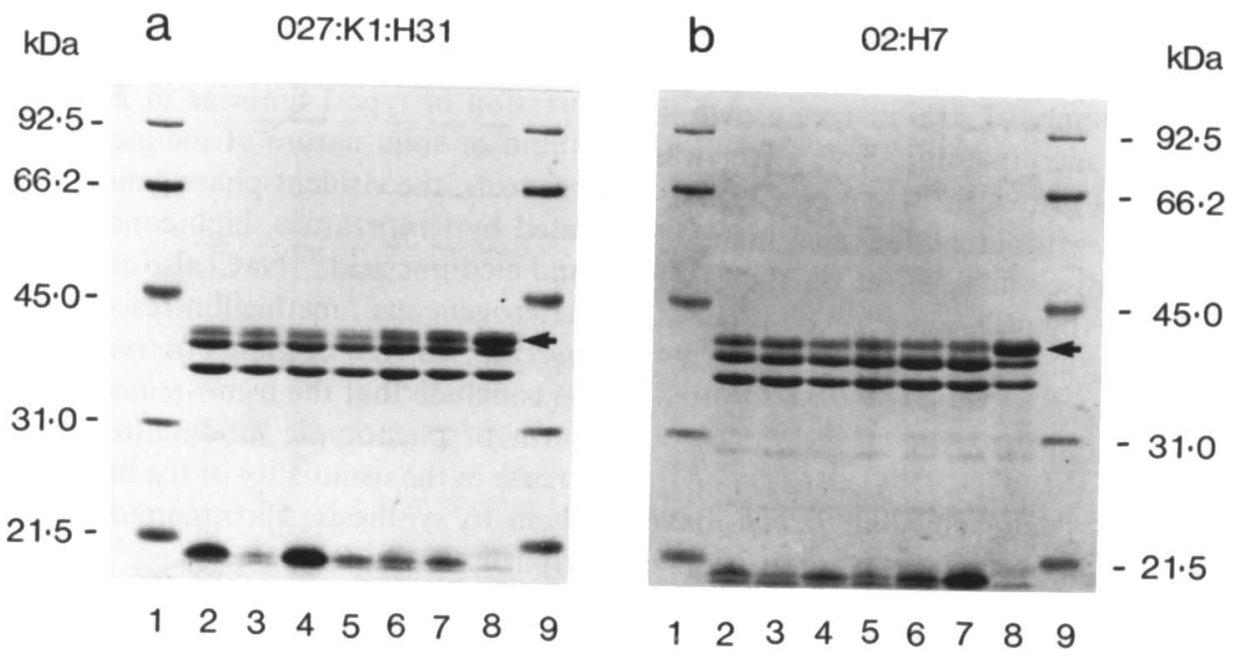

Fig. 3. SDS-PAGE of OMPs of $E$. coli $\mathrm{O} 27: \mathrm{K} 1: \mathrm{H} 31$ (a) and $E$. coli $\mathrm{O} 2: \mathrm{H} 7$ (b) grown in MM or TSB. Lanes 1 and 9 , $\mathrm{M}_{\mathrm{r}}$ markers; 2 , MM with $0.2 \mathrm{M} \mathrm{NaCl} ; 3, \mathrm{MM}$ with $0.2 \mathrm{M} \mathrm{NaCl}$ and $1 \mathrm{mM}$ nicotinamide; 4 , MM with $0.4 \mathrm{M}$ mannitol; 5 , MM with $0.4 \mathrm{M}$ mannitol and $\mathrm{ImM}$ nicotinamide; 6 , TSB $; 7$, TSB with $1 \mathrm{mM}$ nicotinamide $; 8$, MM with $1 \mathrm{mM}$ nicotinamide. The arrows point to the increased amount of $o m p F$ noted in lane 8 for each strain. 
$\mathrm{kDa}$

K10

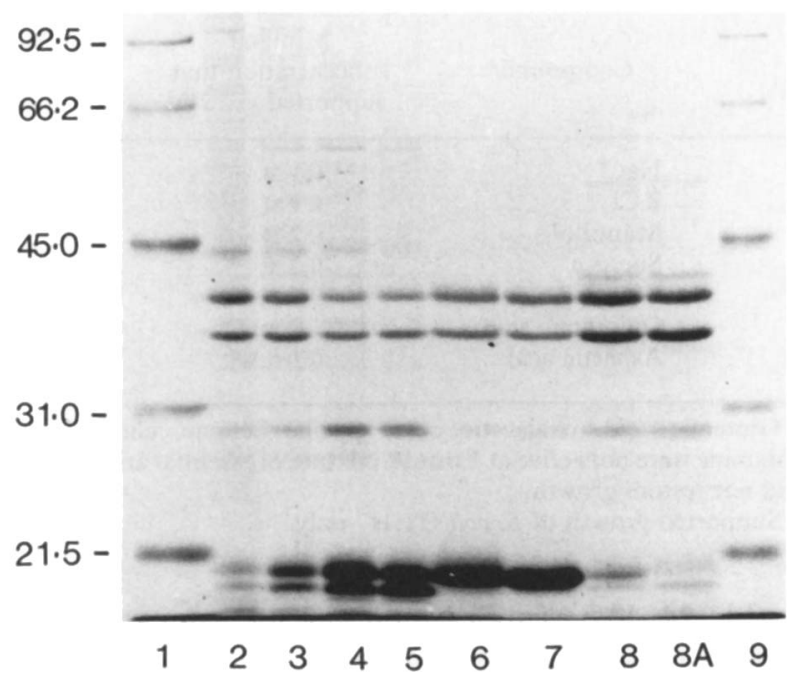

Fig. 4. SDS-PAGE of OMPs of E. coli $\mathrm{K} 10$ grown in MM or TSB. Lanes 1 and $9 . \mathrm{M}_{\mathrm{r}}$ markers; $2, \mathrm{MM}$ with $0.2 \mathrm{M} \mathrm{NaCl} ; 3, \mathrm{MM}$ with $0.2 \mathrm{M} \mathrm{NaCl}$ and $1 \mathrm{mM}$ nicotinamide $; 4, \mathrm{MM}$ with $0.4 \mathrm{M}$ mannitol $; 5$, MM with $0.4 \mathrm{M}$ mannitol and $1 \mathrm{mM}$ nicotinamide; 6 , TSB; 7, TSB with $1 \mathrm{mM}$ nicotinamide $; 8$, MM with $1 \mathrm{mM}$ nicotinamide; 8 A, MM alone.

penicillinase. The plate was then streaked across its diameter with $0.001 \mathrm{ml}$ of an osmo-tolerant strain of $E$. coli $\mathrm{K} 10$ grown in MM (fig. 2). The satellites seen in the region of the streak indicate that nutrients had diffused from the $E$. coli $\mathrm{K} 10$ to support growth of the osmo-remedial strain.

\section{Characterisation of OMP proteins of the osmo- remedial strains}

Representative strains of $E$. coli $\mathrm{O} 27: \mathrm{H} 7$ and K10, which had been treated with ampicillin and penicillinase, were incubated for $24 \mathrm{~h}$ at $37^{\circ} \mathrm{C}$ in $\mathrm{MM}$ containing $0.2 \mathrm{M} \mathrm{NaCl}, 0.4 \mathrm{M}$ mannitol or $1 \mathrm{~mm}$ nicotinamide or in TSB with and without nicotinamide. The OMPs were harvested and identified by gel electrophoresis (fig. 3). The most striking finding was the consistent presence of a dense band in the region of $o m p F$ when the osmo-remedial strains were grown in MM containing $1 \mathrm{mM}$ nicotinamide. This effect was not observed with cells grown in $\mathrm{MM}+\mathrm{NaCl}$, mannitol or TSB with or without added nicotinamide. Nicotinamide had no discernible effect on the OMP patterns of E. coli $\mathrm{K} 10$ (fig. 4).

\section{Discassion}

Naturally-occurring, osmo-remedial $E$. coli have not, to our knowledge, been reported previously. The two osmo-remedial clones of $E$. coli described here differed from each other in serotype, fimbrial characteristics, antibiotic susceptibility and chromosomal DNA patterns. The mechanisms that account for the inability of the osmo-remedial variants to grow at low osmolality and their reversion to osmo-tolerant forms are not entirely clear. Several possibilities may be considered.

Firstly, E. coli responds to low osmolality by increasing the synthesis of membrane-derived oligosaccharides (MDO) ${ }^{14}$ and the $o m p F$ porin. ${ }^{15-17}$ MDO is localised in the periplasm and thought to be one of several mechanisms by which gram-negative bacteria cope with low osmolality; ompF permits the uptake of relatively large hydrophobic or negatively-charged compounds. ${ }^{18.19}$ Mutants of $E$. coli unable to synthesise MDO exhibit decreased expression of ompF when grown in medium of low osmolarity and ionic strength. ${ }^{20}$ It has been proposed that a minimal ionic strength in the periplasm is necessary for normal porin regulation. ${ }^{21}$

It is possible that the osmo-remedial strains are unable to respond to low osmolality by synthesis of MDO and ompF. This is supported, in part, by the finding that ompF was increased by nicotinamide under hypotonic conditions. The effect was abolished when the osmolality of the medium was increased by adding $\mathrm{NaCl}$ or mannitol.

Secondly, Env A permeability mutants of $E$. coli which allow periplasmic $\beta$-lactamase and RNAase I to leak into the medium have been described. ${ }^{22}$ These mutants are highly susceptible to a wide variety of antibiotics including erythromycin and vancomycin. It is doubtful whether the osmo-remedial strains have a defect since they were resistant to these drugs.

Finally, a critical osmolality, ionic strength or temperature is often necessary for the phenotypic expression of enzyme activity in mutant bacteria. ${ }^{23}$ Temperature-sensitive mutants of $E$. coli ${ }^{24}$ and saltcorrectable, temperature-sensitive, histidine auxotrophs of Salmonella typhimurium ${ }^{23}$ have been described. There are also reports of osmo-remedial adenine- and glutamate-requiring, and ionic strengthremedial pantothenate mutants of Neurospora crassa. ${ }^{25-27}$ Similar effects have been described in auxotrophic mutants of yeasts. ${ }^{28}$

Phase variation and phenotypic modulation is fairly common among micro-organisms. For example, expression of type I fimbriae in $E$. coli depends on the liquid or solid nature of the medium. ${ }^{29}$ In Bordetella pertussis, the virulent-phase genes are reversibly regulated by temperature, high concentrations of $\mathrm{MgSO}_{4}$ and nicotinic acid. ${ }^{30} \mathrm{NaCl}$ also effects the expression of heterogeneous methicillin-resistant Staphylococcus aureus. ${ }^{31}$ In view of these observations, it is reasonable to conclude that the osmo-remedial variants exhibit a form of phenotypic modulation, induced by an increase in the osmolality of the medium, which permits them to synthesise nicotinamide from precursors of aspartic or quinolinic acids.

The osmo-remedial, nicotinamide-requiring strains do not appear to have a disadvantage for survival in nature, since they were readily isolated from clinical specimens. This may be due to the relative abundance of nicotinamide in body fluids ${ }^{32}$ or because protective 
compounds may be derived from other bacteria growing in the same environment.

\section{References}

1. Ingraham J. Effect of temperature, $\mathrm{pH}$, water activity, and pressure on growth. In: Neidhardt FC (ed) Escherichia coll and Salmonella typhimurium cellular and molecular biology, vol. 2. Washington, American Society for Microbiology. 1987: 1543-1554.

2. Achtman M, Mercer A, Kusecek B et al. Six widespread bacterial clones among Escherichia coli $\mathrm{K} 1$ isolates. Infect Immun 1983; 39: 315-335.

3. Nimmich W, Zingler G. Biochemical characteristics, phage patterns, and $\mathrm{Ol}$ factor analysis of Escherichia col $\mathrm{O} 1: \mathrm{K} 1: \mathrm{H} 7: \mathrm{F} 11$ and $\mathrm{O} 1: \mathrm{K} 1: \mathrm{H}^{-}: \mathrm{F} 9$ strains isolated from patients with urinary tract infections. Med Microbiol Immunol 1984; 173: 75-85.

4. Robeson JP, Goldschmidt RM, Curtiss R. Potential of Escherichia coli isolated from nature to propagate cloning vectors. Nature 1980; 283: 104-106.

5. Gillespie WA. Biochemical mutants of coliform bacilli in infections of the urinary tract. $J$ Pathol Bacteriol 1952; 64 : $551-557$.

6. McIver CJ, Tapsall JW. Cysteine requirements of naturally occurring cysteine auxotrophs of Escherichia coli. Pathology $1987 ; 19: 361-363$.

7. Davis BD. The isolation of biochemically deficient mutants of bacteria by means of penicillin. Proc Natl Acad Sci USA $1949 ; 35: 1-10$

8. Le Rudulier D, Strom AR, Dandekar AM, Smith LT, Valentine RC. Molecular biology of osmoregulation. Science 1984 224: 1064-1068

9. Davis BD, Mingioli ES. Mutants of Escherichia coli requiring methionine or vitamin $B_{12} . J$ Bacteriol $1950 ; 60$ : 17-28.

10. Laemmli UK. Cleavage of structural proteins during the assembly of the head of bacteriophage T4. Nature 1970; 227: $680-685$.

11. Van Ketel RJ, ter Schegget J, Zanen HC. Molecular epidemiology of Legionella pneumophila serogroup 1. I Clin Microbiol 1984; 20: 362-364.

12. Maniatis T, Fritsch EF, Sambrook J. Molecular cloning: a laboratory manual. Cold Spring Harbor, NY, Cold Spring Harbor Laboratory. 1982: 451.

13. Kado CI, Liu ST. Rapid procedure for detection and isolation of large and small plasmids. J Bacteriol 1981; 145 : $1365-1373$.

14. Kennedy EP. Osmotic regulation and the biosynthesis of membrane-derived oligosaccharides in Escherichia coli. Proc Natl Acad Sci USA 1982; 79: 1092-1095.

15. Barron A, May G, Bremer E, Villarejo M. Regulation of envelope protein composition during adaptation to osmotic stress in Escherichia coli. $J$ Bacteriol 1986; 167: 433-438.
We wish to acknowledge Dr Linda Tombras Smith, University of California, Davis, for helpful advice during the course of these studies.

16. Lugtenberg B, Peters R, Bernheimer A, Benendson W. Influence of cultural conditions and mutations on the composition of the outer membrane proteins of Escherichia coli. Mol Gen Genet 1976; 147: 251-262.

17. Van Alphen WV, Lugtenberg B. Influence of osmolarity of the growth medium on the outer membrane protein pattern of Escherichia coli. J Bacteriol 1977; 131: 623-630.

18. Jaffe A, Chabbert YA, Semonin O. Role of porin proteins $\mathrm{OmpF}$ and OmpC in the permeation of beta-lactams. Antimicrob Agents Chemother 1982; 22: 942-948.

19. Nikaido H, Rosenberg EY, Foulds J. Porin channels in Escherichia coli: studies with $\beta$-lactams in intact cells. $J$ Bacteriol 1983; 153: 232-240.

20. Fielder W, Rotering H. Properties of Escherichia coli mutants lacking membrane-derived oligosaccharides. J Biol Chem 1988; 263: 14684-14689.

21. Geiger O, Russo FD, Silhavy TJ, Kennedy EP. Membranederived oligosaccharides affect porin osmoregulation only in media of low ionic strength. $J$ Bacteriol $1992 ; 174$ : 1410-1413.

22. Young K, Silver LL. Leakage of periplasmic enzymes from envAI strains of Escherichia coli. J Bacteriol 1991; 173: 3609-3614.

23. Kohno T, Roth J. Electrolyte effects on the activity of mutant enzymes in vivo and in vitro. Biochemistry 1979; 18: 1386-1392.

24. Russell RRB. Temperature-sensitive osmotic remedial mutants of Escherichia coli. J Bacteriol 1972; 112: 661-665.

25. Fincham JRS, Baron AJ. The molecular basis of an osmotically reparable mutant of Neurospora crassa producing unstable glutamate dehydrogenase. J Mol Biol 1977; 110: 627-642.

26. Martin CE, DeBusk AG. Temperature-sensitive, osmoticremedial mutants of Neurospora crassa: osmotic pressure induced alterations of enzyme stability. Mol Gen Genet $1975 ; 136: 31-40$.

27. Ryan FJ, Kunin CM, Ballentine R, Maas W. Unique sensitivity of a panthothenicless mutant of Neurospora to constituents of the growth medium. $J$ Bacteriol 1953; 65: 434- 439.

28. Hawthorne DC, Friis J. Osmotic-remedial mutants. A new classification for nutritional mutants in yeast. Genetics $1964 ; 50: 829-839$.

29. Eisenstein BI. Type 1 fimbriae of Escherichia coli: genetic regulation, morphogenesis, and role in pathogenesis. Rev Infect Dis 1988; 10 Suppl 2: S341-S344.

30. Weiss AA, Hewlett EL. Virulence factors for Bordetella pertussis. Annu Rev Microbiol 1986; 40: 661-686.

31. Chambers HF, Hackbarth $\mathrm{CJ}$. Effect of $\mathrm{NaCl}$ and nafcillin on penicillin-binding protein $2 a$ and heterogeneous expression of methicillin resistance in Staphylococcus aureus. Antimicrob Agents Chemother 1987; 31: 1982-1988.

32. Weiner M, Van Eys J. Nicotinic acid. Nutrient-cofactor-drug New York, Marcel Dekker, Inc. 1983. 